\title{
$\left.{ }^{c \mid \rho p}\right|_{E}$
}

\section{What to do if you suspect an ethical problem with a submitted manuscript}

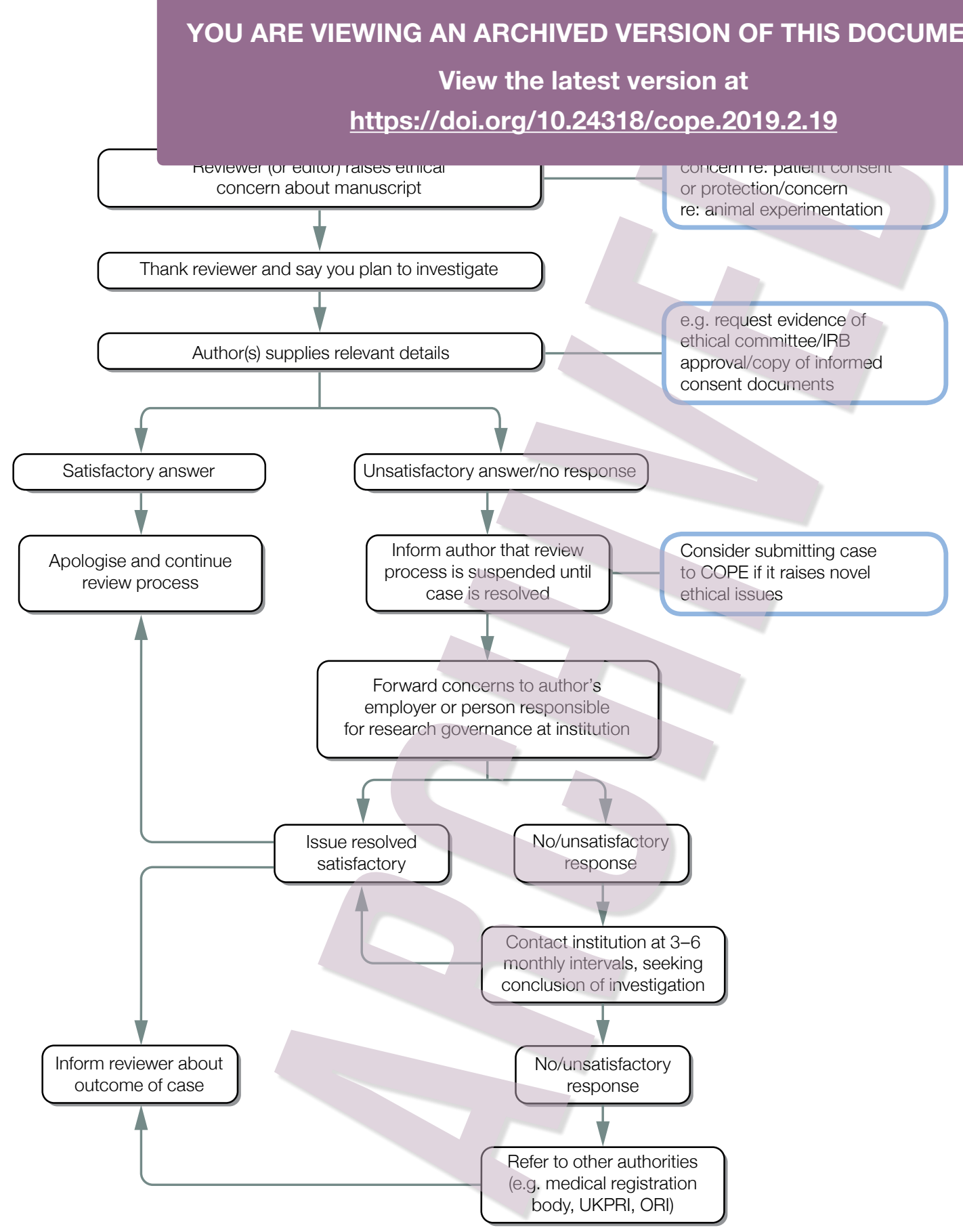

Developed for COPE by Liz Wager of Sideview (www.lizwager.com) (C) 2013 Committee on Publication Ethics First published 2006 